\title{
ANALISIS KEKUATAN TARIK DAN IMPAK MATERIAL KOMPOSIT POLIMER DALAM APLIKASI FIBERBOAT
}

\author{
Rezza Ruzuqi ${ }^{1, *}$ dan Victor Danny Waas ${ }^{2}$ \\ ${ }_{1}^{1}$ Program Studi Mekanisasi Perikanan Politeknik Kelautan dan Perikanan Sorong, Sorong 98411 \\ *Email: rezza ruzuqi@yahoo.co.id \\ 2 Program Studi Teknik Mesin Fakultas Teknik Universitas Pattimura, Ambon 97233 \\ Email : victorwaas90@gmail.com
}

\begin{abstract}
Abstrak. Material komposit merupakan material yang memiliki sistem multi fasa yang tersusun atas bahan penguat dan bahan matriks. Hal tersebut menyebabkan material komposit memiliki keunggulan dalam berbagai hal seperti densitas rendah, sifat mekanik tinggi, kinerja yang sebanding dengan logam, tahan terhadap korosi dan mudah untuk difabrikasi. Dalam bidang industri kelautan dan perikanan, material komposit berbahan penguat fiber terutama fiberglass terbukti sangat istimewa dan populer dalam konstruksi perahu karena memiliki keuntungan menjadi lembam secara kimia (baik diaplikasikan pada lingkungan umum maupun dalam lingkungan laut), ringan, kuat, mudah dicetak, dan harga bersaing. Dengan begitu dalam penelitian ini, dilakukan metode tarik dan impak dalam mengetahui sifat mekanik material komposit polimer fiberglass. Setiap pengujian, dilakukan terhadap variasi jumlah laminasi fiberglass CSM 300, CSM 450 dan WR 600 dan variasi persentase berat $99,5 \%-0,5 \%, 99 \%-1 \%, 98.5 \%-1,5 \%, 98 \%$ $2 \%$ dan $97.5 \%-2.5 \%$ telah digunakan. Hasil penelitian menunjukkan bahwa semakin banyak jumlah laminasi semakin besar kekuatan impak, yaitu sebesar $413.712 \mathrm{MPa}$, dan semakin banyak persentase pengeras semakin besar kekuatan impak, yakni sebesar 416.487 MPa. Hasil penelitian menunjukkan bahwa semakin banyak laminasi kekuatan tarik meningkat, yaitu sebesar 87,054 Mpa, dan semakin banyak persentase pengeras semakin menurunkan kekuatan tarik, yakni sebesar 73.921 MPa.
\end{abstract}

Kata kunci: Kuat Tarik, Kuat Impak, Material Komposit Polimer berpenguat Fiberglass

\begin{abstract}
Composite material is a material that has a multi-phase system composed of reinforcing materials and matrix materials. Causes the composite materials to have advantages in various ways such as low density, high mechanical properties, performance comparable to metal, corrosion resistance, and easy to fabricate. In the marine and fisheries industry, composite materials made from fiber reinforcement, especially fiberglass, have proven to be very special and popular in boat construction because they have the advantage of being chemically inert (both applied in general and marine environments), light, strong, easy to print, and price competitiveness. Thus in this study, tensile and impact methods were used to determine the mechanical properties of fiberglass polymer composite materials. Each test is carried out on variations in the amount of fiberglass laminate CSM 300, CSM 450 and WR 600 and variations in weight percentage $99.5 \%-0.5 \%, 99 \%-1 \%, 98.5 \%-1,5 \%, 98 \%-2 \%$ and $97.5 \%-2.5 \%$ have been used. The results showed that the greater the number of laminates, the greater the impact strength, which was 413,712 MPa, and the more the percentage of hardener, the greater the impact strength, which was 416,487 MPa. The results showed that the more laminate the tensile strength increased, which was $87.054 \mathrm{MPa}$, and the more the percentage of hardener, the lower the tensile strength, which was $73.921 \mathrm{MPa}$.
\end{abstract}

Keywords: Tensile Strength, Impact Strength, Fiberglass Reinforced Polymer Composite Materials 


\section{PENDAHULUAN}

Material komposit adalah sejenis sistem multi-komponen yang kompleks, dan sulit untuk didefinisikan secara akurat. Definisi ringkas diperlihatkan: material komposit adalah material kombinasi multi-fase dari dua atau lebih komponen material dengan sifat berbeda dan bentuk berbeda melalui proses perpaduan, tidak hanya mempertahankan karakteristik utama dari komponen asli, tetapi juga menunjukkan karakter baru yang tidak dimiliki oleh komponen asli [1]. Analogi dari material komposit seperti yang ditunjukkan oleh Gambar 1 .

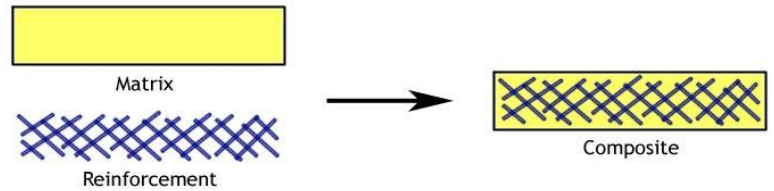

Gambar 1. Analogi material komposit [2]

Kemudian menurut jenis bahan matriks yang digunakan pada material komposit, bahan matriks terdiri atas bahan komposit matriks logam, komposit matriks aluminium dan bahan komposit matriks polimer, Banyak penelitian yang dilakukan menggunakan bahan komposit matriks polimer, seperti yang telah dilakukan oleh [3].

Material komposit selain terdapat jenis bahan matriks, di dalam material komposit juga terdapat bahan penguat baik dari bahan sintetis maupun alami seperti ampas tebu (Bagasse) $[4,5]$.

Selain material komposit polimer berpenguat alami, ada juga yang menggunakan bahan berpenguat sintetis seperti bahan komposit fiberglass (umumnya dikenal sebagai plastik yang diperkuat fiberglass), komposit fibercarbon, dan komposit hybridfiber [6].

Dalam perkembangannya, material komposit banyak sekali diaplikasikan di berbagai bidang industri misalkan industri penerbangan, industri kesehatan, industri kimia, militer, dan lain sebagainya. Dalam bidang pertahanan, pemanfaatan material komposit pada aplikasi militer terbukti dapat memberikan peforma yang lebih baik dibandingkan dengan material logam terutama dalam meningkatkan kemampuan mobilitas dari personil pertahanan [7]. Kemudian untuk industri penerbangan, material komposit polimer digunakan untuk menahan persebaran api di pesawat terbang [8].

Selain digunakan untuk industri pertahanan dan penerbangan, dalam perkembangannya material komposit polimer juga dapat diaplikasikan ke dalam bidang industri kalautan salah satunya sebagai material pembuatan perahu fiber. Meskipun ada sejumlah pilihan bahan penguatan dalam material komposit yang digunakan, tetapi jika ditinjau dari segi ekonomi, material komposit berbahan penguat fiberglass lebih menguntungkan jika dibandingkan dengan karbon dan serat aramid untuk diaplikasikan dalam bidang industri kelautan. Fiberglass dalam ilmu material termasuk kedalam kategori Thermoset Polymer Composites. Memang secara kinerja, kombinasi karbon dan serat aramid memiliki nilai tinggi, tetapi serat gelas masih menyumbang lebih $95 \%$ dari pemanfaatan dalam aplikasi maritim [9]. material komposit berpenguat polimer fiber oleh [10].

Kemudian, agar didapati material komposit polimer yang memiliki kekuatan yang sesuai dengan kebutuhan, maka perlu diketahui sifat mekanik dari bahan tersebut. Salah satu karakterisasi untuk mengetahui sifat mekanik dari suatu material adalah dengan melakukan pengujian tarik [11,12]. Beberapa bahan komposit telah diujikan tarik dengan penguat atau matrix yang berbeda diantaranya resin epoksi-montmorillonit organoklay oleh [13], graphene sebagai pengisi konduktif material komposit dengan memadukan anti-statis Multi-Layer Graphene (MLG) diisi poly vinyl chloride (PVC) oleh [14], dan serat alami seperti abaca, goni dan sisal ditinjau dari kekuatan tarik oleh [15].

Selain menggunakan pengujian tarik, sifat mekanik dari suatu material dapat diketahui menggunakan pengujian impak. Kekuatan impak sebuah material merupakan ketahanan sebuah material terhadap gaya yang diberi secara tiba-tiba. Beberapa bahan komposit telah diujikan impak dengan penguat atau matrix yang berbeda diantaranya polimer termoplastik akrilik Glass Fiber Reinforced (GFR), berdasarkan suhu kamar matriks methyl-methacrylate (MMA) [16], komposit polimer diperkuat serat gelas (GFRPC) memiliki kekuatan rendah dibandingkan dengan komposit polimer diperkuat serat karbon (CFRPC) [17].

\section{BAHAN DAN METODE}

\subsection{BAHAN}

Bahan yang digunakan dalam penelitian ini yaitu Lem Kayu, Papan Triplek, Epoxy Resin Tipe BQTN-EX 157, Hardener tipe MEPOXE (Methyl Ethyl Ketone Peroxide), Mirror Glass, serat WR 600 (Woven Roving), CSM 300 (Chopped Strand Mat) dan CSM 450 (Chopped Strand Mat). 


\subsection{Prosedur Penelitian dan Persamaan}

Prosedur penelitian yang digunakan adalah menimbang dan memadukan antara bahan penguat dengan bahan matriks dengan variasi kadar penguat. Eksperimental desain dan diagram alir pada penelitian ini ditunjukkan pada Tabel 1a dan 1b di bawah ini

Tabel 1a. Eksperimental desain untuk material komposit polimer variasi penguat dengan variasi matriks sampel B1

\begin{tabular}{cccccc}
\hline Urutan & \multicolumn{4}{c}{ Susunan Laminasi } \\
Laminasi: & Sampel A & Sampel A & Sampel A 3 & Sampel A & Sampel A5 \\
\hline Lapisan 1 & CSM 300 & CSM 300 & CSM 300 & CSM 300 & CSM 300 \\
Lapisan 2 & WR 600 & CSM 450 & CSM 450 & CSM 450 & CSM 450 \\
Lapisan 3 & CSM 450 & WR 600 & WR 600 & WR 600 & WR 600 \\
Lapisan 4 & CSM 450 & CSM 450 & CSM 450 & CSM 450 & CSM 450 \\
Lapisan 5 & & CSM 450 & WR 600 & WR 600 & WR 600 \\
Lapisan 6 & & & CSM 450 & CSM 300 & CSM 300 \\
Lapisan 7 & & & & CSM 450 & WR 600 \\
Lapisan 8 & & & & & CSM 450 \\
\hline
\end{tabular}

Tabel 1b. Eksperimental desain untuk material komposit polimer variasi matriks dengan variasi penguat sampel A3

\begin{tabular}{cccccc}
\hline Urutan & \multicolumn{5}{c}{ Prosentase Bobot (\%) } \\
Laminasi & Sampel B $_{1}$ & Sampel B & Sampel B & Sampel B & Sampel B \\
\hline Epoxy Resins & 99.5 & 99 & 98.5 & 98 & 97.5 \\
Hardener & 0.5 & 1 & 1.5 & 2 & 2.5 \\
\hline
\end{tabular}

Dalam penelitian ini, untuk mengetahui sifat mekanik material komposit polimer dilakukan karakterisasi menggunakan pengujian tarik. Selanjutnya untuk sampel uji tarik, spesimen dibuat mengacu pada ASTM D3039/D3039M, seperti yang ditunjukkan oleh Gambar 2 dan Tabel 2 menunjukkan geometri spesimen yang dibutuhkan.
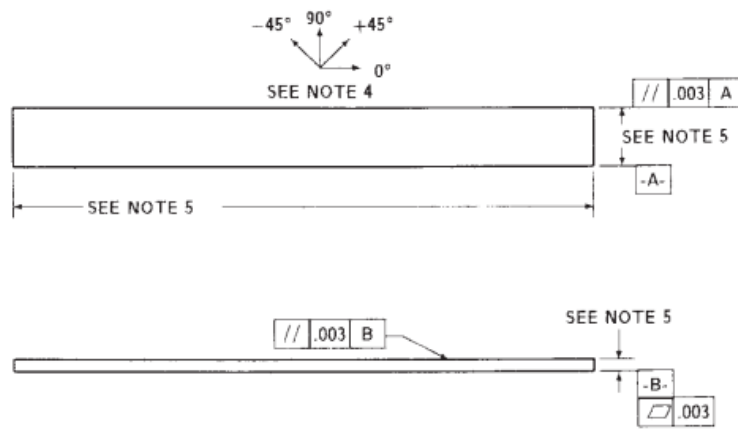

Gambar 2. Spesimen uji tarik (ASTM D3039/D3039M)
Tabel 2. Geometri specimen uji tarik

\begin{tabular}{ccccccc}
$\begin{array}{c}\text { Orientasi } \\
\text { Fiber }\end{array}$ & $\begin{array}{c}\text { Lebar, } \\
\mathrm{mm} \\
\text { (in.) }\end{array}$ & $\begin{array}{c}\text { Panjang } \\
\text { Keseluruhan } \\
\text { (in.) }\end{array}$ & $\begin{array}{c}\text { Tebal } \\
\mathrm{mm} \\
\text { (in.) }\end{array}$ & $\begin{array}{c}\text { Panjang } \\
\text { Tab(in.) }\end{array}$ & $\begin{array}{c}\text { Tebal } \\
\text { Tab } \\
\text { (in.) }\end{array}$ & $\begin{array}{c}\text { Sudut } \\
\text { Tab } \\
\text { Bevel }\left({ }^{\circ}\right)\end{array}$ \\
\hline Arah $0^{0}$ & 15 & 250 & 1,0 & 56 & 1,5 & 7 atau 90 \\
& $(0,5)$ & $(10,0)$ & $(0,040)$ & $(2,25)$ & $(0,062)$ & 1,5 \\
Arah $90^{\circ}$ & 25 & 175 & 2,0 & 25 & 90 \\
& $(1,0)$ & $(7,0)$ & $(0,080)$ & $(1,0)$ & $(0,062)$ & 90 \\
Keseimbangan & 25 & 250 & 2,5 & - & - & - \\
dan Simetrik & $(1,0)$ & $(10,0)$ & $(0,100)$ & & & - \\
Diskontinyu & 25 & 250 & 2,5 & - & - & - \\
acak & $(1,0)$ & $(10,0)$ & $(0,100)$ & - & & \\
\hline
\end{tabular}

Dalam penelitian ini, untuk mengetahui sifat mekanik material komposit polimer selain dilakukan karakterisasi menggunakan pengujian tarik, bisa juga menggunakan uji impak. Kekuatan impak sebuah material merupakan ketahanan sebuah material terhadap gaya yang diberi secara tiba-tiba. Untuk mendapatkan nilai uji impak, beberapa parameter dimasukkan ke dalam persamaan

$$
\text { IS }=\frac{E 1}{A}=\frac{W \cdot \lambda(\cos \beta-\cos \alpha)}{A}
$$

Dengan :

$W \quad=$ Usaha yang diperlukan untuk mematahkan benda uji $(\mathrm{kg} \mathrm{m})$

$\lambda=$ Jarak lengan pengayun $(\mathrm{m})$

$\cos \beta=$ Sudut posisi akhir pendulum

$\cos \alpha=$ Sudut posisi awal pendulum

$A \quad=$ luas penampang di bawah takikan $\left(\mathrm{m}^{2}\right)$

Selanjutnya untuk sampel uji impak, spesimen dibuat mengacu pada ASTM D6110, seperti yang ditunjukkan oleh Gambar 3 dan Tabel 3 menunjukkan geometri spesimen yang dibutuhkan.

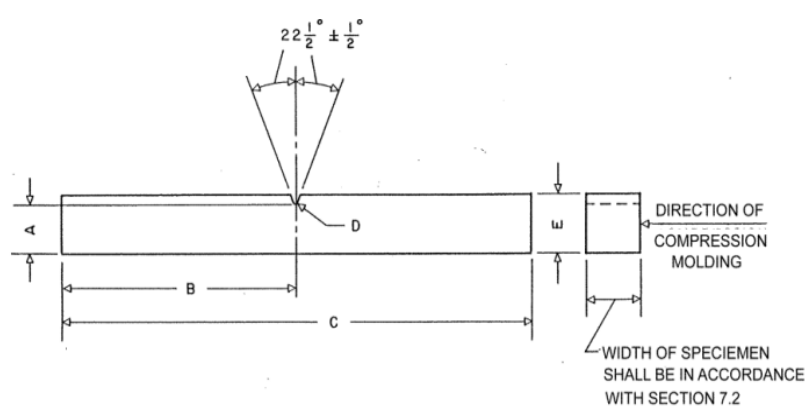

Gambar 3. Spesimen uji impak (ASTM D6110)

Tabel 3. Geometri spesimen uji impak

\begin{tabular}{ccc}
\hline Simbol & Ukuran $(\mathrm{mm})$ & Toleransi (mm) \\
\hline A & $10,16 \pm 0,05$ & $0,400 \pm 0,002$ \\
B & 63,5 & 2,5 \\
& 61,0 & 2,40 \\
C & 127,0 & 5,00 \\
& 124,5 & 4,00 \\
D & $0,25 \pm 0,05$ & $0,010 \pm 0,002$ \\
E & 12,70 & $0,500 \pm 0,006$
\end{tabular}




\section{HASIL DAN PEMBAHASAN}

Sifat mekanik adalah salah satu sifat yang menyatakan kemampuan untuk menerima beban/gaya/energi. Sifat mekanik bahan merefleksikan hubungan antara beban/gaya/energi yang diterima suatu bahan dengan reaksi yang diberikan atau deformasi yang akan terjadi. Sifat mekanik bahan terbagi atas beberapa sifat diantaranya; Kekuatan (strength), Kekerasan (hardness), Kekenyalan (elasticity), Kekakuan (stiffness), Plastisitas (plasticity), Ketangguhan (toughness), Kelelahan (fatigue) dan Keretakan - merangkak (creep-crack).

Kuat tarik merupakan salah satu sifat penting untuk menggambarkan kinerja mekanik material. Dengan menggunakan pengujian tarik, akan didapati besarnya tegangan dan regangan yang dialami sebuah material.

Hasil yang diperoleh dari pengujian tarik yang telah dilakukan pada material komposit polimer fiberglass yakni seperti yang ditunjukkan oleh Tabel 4a dan 4b.

Tabel 4a. Hasil pengujian tarik pada variasi penguat material komposit polimer fiberglass

\begin{tabular}{cc}
\hline Sampel & $\begin{array}{c}\text { Nilai Kuat Tarik } \\
(\mathrm{MPa})\end{array}$ \\
\hline A1 & 59.467 \\
A2 & 63.722 \\
A3 & 75.816 \\
A4 & 82.899 \\
A5 & 87.054 \\
\hline
\end{tabular}

Dari Tabel 4a, diperoleh nilai kuat tarik pada material komposit polimer fiberglass yakni sebesar $\mathrm{A} 1=59.467 \mathrm{MPa}, \mathrm{A} 2=63.722 \mathrm{MPa}$, $\mathrm{A} 3=75.816 \mathrm{MPa}, \mathrm{A} 4=82.899 \mathrm{MPa}$ dan $\mathrm{A} 5=$ $87.054 \mathrm{MPa}$. Hasil tersebut menunjukkan bahwa, material komposit polimer fiberglass bervariasi penguat menghasilkan nilai tarik yang semakin meningkat seiring dengan penambahan penguat pada material tersebut.

Tabel 4b. Hasil pengujian tarik pada variasi matriks material komposit polimer fiberglass

\begin{tabular}{cc}
\hline Sampel & $\begin{array}{c}\text { Nilai Kuat Tarik } \\
(\mathrm{MPa})\end{array}$ \\
\hline B1 & 73.921 \\
B2 & 69.117 \\
B3 & 67.592 \\
B4 & 65.967 \\
B5 & 65.342 \\
\hline
\end{tabular}

Dari Tabel $4 b$, diperoleh nilai kuat tarik pada material komposit polimer fiberglass yakni sebesar $\mathrm{B} 1=73.921 \mathrm{MPa}, \mathrm{B} 2=69.117 \mathrm{MPa}, \mathrm{B} 3=67.592$ $\mathrm{MPa}, \mathrm{B} 4=65.967 \mathrm{MPa}$ dan B5=65.342 MPa. Hasil tersebut menunjukkan bahwa, material komposit polimer fiberglass bervariasi matriks menghasilkan nilai tarik yang semakin menurun seiring dengan penambahan prosentase bobot matriks pada material tersebut.

Kuat impak juga merupakan salah satu sifat penting untuk menggambarkan kinerja mekanik material. Prinsip dari pengujian ini yakni penyerapan energi potensia dari pendulum beban yang berayun dari suatu ketinggian tertentu dan menumbuk benda uji sehingga benda uji mengalami deformasi. Dengan menggunakan pengujian impak, akan didapati besarnya kekuatan, kekerasan, serta keuletan material yang dialami sebuah material.

Hasil yang diperoleh dari pengujian impak yang telah dilakukan pada material komposit polimer fiberglass yakni seperti yang ditunjukkan oleh Tabel 5a dan 5b.

Tabel 5a. Hasil pengujian impak pada variasi penguat material komposit polimer fiberglass

\begin{tabular}{cc}
\hline Sampel & $\begin{array}{c}\text { Nilai Kuat Impak } \\
(\mathrm{MPa})\end{array}$ \\
\hline A1 & 366.297 \\
A2 & 379.859 \\
A3 & 396.756 \\
A4 & 405.392 \\
A5 & 413.712 \\
\hline
\end{tabular}

Dari Tabel 5a., diperoleh nilai kuat impak pada material komposit polimer fiberglass yakni sebesar $\mathrm{A} 1=366.297 \mathrm{MPa}, \mathrm{A} 2=379.859 \mathrm{MPa}, \mathrm{A} 3=$ $396.756 \mathrm{MPa}, \mathrm{A} 4=405.392 \mathrm{MPa}$ dan $\mathrm{A} 5=413.712$ MPa. Hasil tersebut menunjukkan bahwa, material komposit polimer fiberglass bervariasi penguat menghasilkan nilai impak yang semakin meningkat seiring dengan penambahan penguat pada material tersebut.

Tabel 5b. Hasil pengujian impak pada variasi matriks material komposit polimer fiberglass

\begin{tabular}{cc}
\hline Sampel & $\begin{array}{c}\text { Nilai Kuat Impak } \\
(\mathrm{MPa})\end{array}$ \\
\hline B1 & 396.865 \\
B2 & 400.890 \\
B3 & 412.374 \\
B4 & 416.487 \\
B5 & 410.247 \\
\hline
\end{tabular}


Dari Tabel 5b, diperoleh nilai kuat impak pada material komposit polimer fiberglass yakni sebesar B1 $=396.865 \mathrm{MPa}, \mathrm{B} 2=400.890 \mathrm{MPa}$, $\mathrm{B} 3=412.374 \mathrm{MPa}, \mathrm{B} 4=416.487 \mathrm{MPa}$ dan B5= 410.247 MPa. Hasil tersebut menunjukkan bahwa, material komposit polimer fiberglass bervariasi matriks menghasilkan nilai impak yang semakin naik seiring dengan penambahan prosentase bobot matriks pada material tersebut. Akan tetapi terdapat sampel yang menghasilkan kuat impak yang kecil jika dibandingkan jenis sampel sebelumnya.

\section{KESIMPULAN}

Berdasarkan hasil pengujian tarik dan impak material komposit polimer fiberglass dengan masing-masing meninjau pengaruh variasi penguat dan variasi matriks sebagai bahan pembuatan perahu fiberglass yang telah dilakukan dalam penelitian ini, dihasilkan sebuah kesimpulan bahwa variasi penguat berpengaruh terhadap sifat mekanik tarik material komposit polimer fiberglass. Semakin besar lapisan yang diberikan pada material komposit polimer fiberglass, maka nilai kuat tarik pada material tersebut semakin besar, yaitu sebesar 87,054 Mpa. Akan tetapi berbeda dengan hasil yang diperoleh dari material komposit polimer fiberglass variasi matriks. Semakin besar kandungan matriks yang ditambahkan, maka nilai kuat tarik pada material tersebut semakin kecil, yakni sebesar 73.921 MPa. Kemudian untuk kesimpulan berikutnya bahwa pengaruh variasi penguat berpengaruh terhadap sifat mekanik impak material komposit polimer fiberglass. Semakin besar lapisan yang diberikan pada material komposit polimer fiberglass, maka nilai kuat impak pada material tersebut semakin besar, yaitu sebesar 413.712 $\mathrm{MPa}$. Begitu juga dengan hasil yang diperoleh dari material komposit polimer fiberglass variasi matriks. Semakin besar kandungan matriks yang ditambahkan, maka nilai kuat impak pada material tersebut semakin besar, yakni sebesar 416.487 MPa.

\section{UCAPAN TERIMA KASIH}

Ucapan terima kasih disampaikan kepada Pusat Penelitian dan Pengabdian Masyarakat Unit Penelitian Politeknik Kelautan dan Perikanan Sorong.

\section{DAFTAR PUSTAKA}

[1] Wang, R.-M., Zheng, S.-R., \& Zheng, Y.P. (2011). Polymer matrix composites and technology. Beijing: Woodhead
Publishing Limited and Science

PressLimited.

[2] Artikel-teknologi. (2018). Pengertian Material Komposit di http://artikelteknologi.com/pengertian-materialkomposit/, 2018 (diakses 08 Juli)

[3] Naresh, K., Shankar, K., Rao, B., \& Velmurugan, R. (2016). Effect of high strain rate on glass/carbon/hybridfiber reinforced epoxy laminated composites. Composites Part B, 125-135.

[4] Clareyna, E. D., \& Mawarani, L. J. (2013). Pembuatan dan Karakteristik Komposit Polimer Berpenguat Bagasse. TEKNIK POMITS, 208-213.

[5] Minah, F. N., Astuti, S., \& Rastini, E. K. (2017). KARAKTERISASI MATERIAL KOMPOSIT POLIMER POLISTYRENE DAN SERAT TEBU. INDUSTRI INOVATIF, 1-6.

[6] kumre, A., Rana, R., \& Purohit, R. (2017). A Review on mechanical property ofsisal glass fiber reinforced polymer composites. Selection and peer-review under responsibility of Conference Committee Members of 5th International Conference of Bhopal, (hal. 3466-3476).

[7] Mardiyati. (2018). Komposit Polimer Sebagai Material Tahan Balistik. Jurnal Inovasi Pertahanan dan Keamanan, 20-28.

[8] Toldy, A., Szolnoki, B., \& Marosi, G. (2011). Flame retardancy offibre-reinforced epoxy resin composites for aerospace applications. Polymer Degradation and Stability, 371-376.

[9] Shenoi, R. A., \& Dotkins, A. R. (2000). Design of Ships and Marine Structures Made from FRP Composite Materials. Comprehensive Composite Materials, 429449. Southampton: Elsevier Science Ltd.

[10] Mouritz, A., Gellert, E., Burchill, P., \& Challis, K. (2001). Review of Advanced Composite Structures for Naval Ships and Submarines. Composite Structures, 21-41.

[11] Maurin, R., Perrot, Y., Bourmaud, A., Davies, P., \& Baley, C. (2009). Seawater ageing of low styrene emission resins for marine composites: Mechanical behaviour and nano-indentation studies. Composites, 1024-1032.

[12] Zhang, J., Chaisombat, K., He, S., \& Wang, C. H. (2012). Hybrid composite laminates reinforced with glass/carbon woven fabrics for lightweight load bearing structures. Materials and Design, 75-80.

[13] Widyatmaja, D. W., Raharjo, W. W., \& 
Sukanto, H. (2014). pengaruh suhu pencampuran terhadap kekuatan tarik dan fracture toughness epoxy resin organoclay montmorillonite nanokomposit. MEKANIKA, 101-107.

[14] Wang, H., Xie, G., Fang, M., Ying, Z., Tong, Y., \& Zeng, Y. (2015). Electrical and mechanical properties of antistatic PVCfilms containing multi-layer graphene. Composites, 444-450.

[15] Elanchezhian, C., Vijaya Ramnath, B., Ramakrishnan, G., Rajendrakumar, M., Naveenkumar, V., \& Saravanakumar, M. K. (2018). Review on mechanical properties of natural fiber composites. Selection and Peer-review under responsibility of International Conference on Processing of Materials, Minerals and Energy, 1785-1790.

[16] Dossou, G. K., Boumbimba, R. M., Bonfoh, N., Hernandez, S. G., Gonzalez, D. G., Gerard, P., et al. (2019). Innovative acrylic thermoplastic composites versus conventionalcomposites: improving the impact performances. Composite Structures, $1-13$.

[17] Jesthi, D. K., \& Nayak, R. K. (2019). Improvement of Mechanical Properties of Hybrid Composite through Interply Rearrangement of Glass and Carbon Woven Fabrics for Marine Applications. Composites Part B, 467-475. 